ONLINE MUTATION REPORT

\title{
Spectrum of splicing errors caused by CHRNE mutations affecting introns and intron/exon boundaries
}

\author{
K Ohno, A Tsujino, X-M Shen, M Milone, A G Engel
}

J Med Genet 2005;42:e53 (http://www.jmedgenet.com/cgi/content/full/42/8/e53). doi: 10.1136/jmg.2004.026682

\begin{abstract}
Background: Mutations in CHRNE, the gene encoding the muscle nicotinic acetylcholine receptor $\epsilon$ subunit, cause congenital myasthenic syndromes. Only three of the eight intronic splice site mutations of CHRNE reported to date have had their splicing consequences characterised.

Methods: We analysed four previously reported and five novel splicing mutations in CHRNE by introducing the entire normal and mutant genomic CHRNEs into COS cells.

Results and conclusions: We found that short introns (82109 nucleotides) favour intron retention, whereas medium to long introns (306-1210 nucleotides) flanking either or both sides of an exon favour exon skipping. Two mutations are of particular interest. Firstly, a $G \rightarrow$ T substitution at the $3^{\prime}$ end of exon 8 predicts an R286M missense mutation, but instead results in skipping of exon 8 . In human genes, a mismatch of the last exonic nucleotide to UI snRNP is frequently compensated by a matching nucleotide at intron position +6. CHRNE intron 8 has a mismatch at position +6 , and accordingly fails to compensate for the exonic mutation at position -1 . Secondly, a 16 bp duplication, giving rise to two 3' splice sites (g.IVS10-9_c. 1167dup16), results in silencing of the downstream $3^{\prime}$ splice site. This conforms to the scanning model of recognition of the $3^{\prime}$ splice site, which predicts that the first "ag" occurring after the branch point is selected for splicing.
\end{abstract}

$M$ olecular defects of presynaptic, synaptic, or postsynaptic proteins at the motor endplate impair neuromuscular transmission and result in congenital myasthenic syndromes (CMS). ${ }^{1}$ Mutations in the acetylcholine receptor $(\mathrm{AChR}) \in$ subunit gene (CHRNE; OMIM 100725) cause endplate AChR deficiency and/or kinetic abnormalities of AChR. CHRNE mutations causing endplate AChR deficiency include 13 missense, 27 frameshift, 6 nonsense, 8 splice site, 3 promoter region, and 1 chromosomal microdeletion mutations. ${ }^{1}$ Only three of the eight splice site mutations have had their consequences characterised: IVS7-2A $\rightarrow \mathrm{G}^{2}$ and IVS9+ $\mathrm{lG} \rightarrow \mathrm{T}^{3}$ result in skipping of an adjacent exon, and IVS9-IG $\rightarrow$ C causes retention of intron 9. ${ }^{4}$ Four of the five uncharacterised mutations were reported by us. Exclusive expression of CHRNE by subsynaptic nuclei has previously prevented analysis of splicing consequences of these mutations. We recently reported that the cloned entire CHRNE exhibits the same splicing properties as its pre-mRNA in the native state in transfected COS cells. ${ }^{4}$ Therefore we used this method to analyse the splicing consequences of four previously reported and five novel splice site mutations in CHRNE.

\section{MATERIALS AND METHODS}

All human studies were in accord with the guidelines of the institutional review board of the Mayo Clinic.

\section{Patients}

Patients 1-5 (respectively a 59 year old woman, a 23 year old man, a 2.5 year old girl, a 6 year old boy, and a 44 year old man) have moderate to severe myasthenic symptoms that have been present since birth or infancy, decremental EMG responses, and no AChR antibodies. All respond partially to pyridostigmine. Patient 4 underwent an intercostal muscle biopsy for diagnosis, which showed severe endplate AChR deficiency ( $6 \%$ of normal) and compensatory expression of the fetal $\gamma$-AChR at the endplate.

\section{Construction of CHRNE clones for splicing analysis}

To examine the consequences of the identified splice site mutations, we used the previously constructed pRBG4CHRNE plasmid, which carries a cytomegalovirus (CMV) promoter and the entire CHRNE spanning 12 exons and 11 introns. ${ }^{4}$ For extended analysis of g.IVS10-9_c.1167dup16, we also constructed a pRBG4 minigene, spanning nucleotide 880 in exon 9 to nucleotide 1457 in exon 12, where position +1 represents the first nucleotide of the first codon of the mature peptide.

Mutations were engineered using the QuikChange Site Directed Mutagenesis kit (Stratagene). Presence of the expected mutation and absence of unwanted artefacts were confirmed by sequencing the entire insert.

\section{Reverse transcription PCR analysis of cytoplasmic RNA of transfected COS cells}

Wild type and mutant CHRNE clones were introduced into COS7 cells, and cytoplasmic total RNA was isolated as described. ${ }^{4}$ We used two or more sets of PCR primers for each construct to screen for skipping of an exon and retention of an intron.

\section{RESULTS}

\section{Each patient carries two mutant CHRNE alleles}

We detected a total of seven CHRNE mutations in five patients (table 1). Patients 1, 2, and 3 carry homozygous splice site mutations. Five mutations affect pre-mRNA splicing. Analysis of family members reveals that affected siblings carry two mutant CHRNE alleles, whereas unaffected relatives harbour one or no mutant allele (data not shown), indicating that each mutation is recessive.

\section{Splicing consequences of five novel and four previously reported mutations}

Muscle mRNA was available only from patient 4. In this patient, RT-PCR analysis revealed that 1259del23 causes retention of intron 11 (fig 1 , table 1 ). As no muscle specimens were available from the other patients for mRNA analysis, we introduced the four novel (table 1) and the four previously reported (table 2) splice site mutations into the cloned entire CHRNE and analysed the cytoplasmic RNA of the transfected COS cells by RT-PCR. Unlike minigenes, entire CHRNE clones mostly yielded a single splicing product. RT-PCR analysis revealed that IVS4-2A $\rightarrow$ C, IVS6 $+1 G \rightarrow T$, IVS10 $+2 T \rightarrow G$, and 


\begin{tabular}{|c|c|c|c|}
\hline No. & Mutation & $\begin{array}{l}\text { Position on } \\
\text { genomic DNA }\end{array}$ & $\begin{array}{l}\text { Splicing } \\
\text { consequence }\end{array}$ \\
\hline 1 & g.IVS6-1G $\rightarrow C^{*}$ & $\begin{array}{l}3^{\prime} \text { splice site of } \\
\text { intron } 6\end{array}$ & $\begin{array}{l}\text { Active cryptic 3' } \\
\text { splice site† }\end{array}$ \\
\hline 2 & g.IVS9-1G $\rightarrow A^{*}$ & $\begin{array}{l}3^{\prime} \text { splice site of } \\
\text { intron } 9\end{array}$ & $\begin{array}{l}\text { Retention of } \\
\text { intron 9† } \\
\text { Skipping of } \\
\text { exon 10† }\end{array}$ \\
\hline 3 & g.IVS10-9_c.1167dup16* & $\begin{array}{l}16 \mathrm{bp} \\
\text { duplication } \\
\text { comprising } 8 \text { bp } \\
\text { at } 3^{\prime} \text { end of } \\
\text { intron } 10 \text { and } \\
8 \text { bp at } 5^{\prime} \text { end of } \\
\text { exon } 11\end{array}$ & $\begin{array}{l}\text { Silencing of } \\
\text { downstream 3' } \\
\text { splice sitet }\end{array}$ \\
\hline \multirow[t]{2}{*}{4} & c. 1259 _g.IVS1 1+15del23 & $\begin{array}{l}23 \text { bp deletion } \\
\text { comprising } 8 \text { bp } \\
\text { at } 3^{\prime} \text { end of exon } \\
11 \text { and } 15 \text { bp at } \\
5^{\prime} \text { end of intron } \\
11\end{array}$ & $\begin{array}{l}\text { Retention of } \\
\text { intron } 11 \ddagger\end{array}$ \\
\hline & c. $1033 \mathrm{delG}$ & $\begin{array}{l}\text { exon } 10 \text { (61st } \\
\text { nucleotide) }\end{array}$ & NA \\
\hline \multirow[t]{2}{*}{5} & c. $857 \mathrm{G} \rightarrow \mathrm{T}(\mathrm{p} . \mathrm{R} 286 \mathrm{M})$ & $\begin{array}{l}G \rightarrow T \text { substitution } \\
\text { at } 3^{\prime} \text { end of exon } \\
8\end{array}$ & $\begin{array}{l}\text { Skipping of } \\
\text { exon } 8 \dagger\end{array}$ \\
\hline & c.734C $\rightarrow T$ (p.P245L§) & $\begin{array}{l}\text { exon } 7 \text { (193rd } \\
\text { nucleotide) }\end{array}$ & NA \\
\hline
\end{tabular}

*Homozygous mutation. †Characterised using transfected COS cells. ‡Characterised using muscle mRNA. NA, not applicable. §We previously reported that P245L is a low expressor mutation that also prolongs channel opening events two fold. ${ }^{18}$

$857 \mathrm{G} \rightarrow \mathrm{T}$ cause skipping of an adjacent exon; IVS7+2T $\rightarrow \mathrm{C}$ and $1259 \mathrm{del} 23$ result in retention of the mutant intron; IVS9$\mathrm{IG} \rightarrow \mathrm{A}$ causes both exon skipping and intron retention; IVS6$\mathrm{lG} \rightarrow \mathrm{C}$ activates a cryptic $3^{\prime}$ splice site; and g.IVS 109_c.1167dupl6 silences the downstream copy of the 3' splice site (fig 1, tables 1 and 2).

\section{Why is the downstream copy of duplicated 3' splice sites silent?}

The 16 bp duplication (g.IVS10-9_c.1167dupl6) generates two copies of $3^{\prime}$ splice sites, but only the upstream copy is used for splicing. To understand the underlying mechanism, we engineered a series of artificial mutations into a minigene spanning CHRNE exons 9 to 12 (fig 2A and B).

Firstly, we examined a role of the polypyrimidine tract of the upstream and downstream copies (fig 2C). The pyrimidine ratios in the polypyrimidine tract are the same for the two copies $(18 / 24=75 \%$ for the upstream copy and $30 / 40=75 \%$ for the downstream copy), and are not likely to account for selection of the splice site. Substitution of "ac" for the invariant "ag" dinucleotide of the upstream copy activated the downstream copy (Mt-AC in fig 2D), indicating that the increased distance from the branch point to the "ag" dinucleotide does not hinder splicing. Because a stretch of $\mathrm{t}$ bases in the polypyrimidine tract is more efficient in splicing than c bases, ${ }^{5}$ we mutated "cctt" to "tctt" (Mt-TC), "cttt" (Mt-CT), and "tttt" (Mt-TT), but none activated the downstream copy (fig 2D).

The role of the branch point sequence was then examined. Displacement of an invariant " $a$ " nucleotide downstream (Mt-Brl in fig 2E), disruption of the native branch point sequence (Mt-Br2 in fig $2 \mathrm{E}$ ), or both (Mt-Br3 in fig $2 \mathrm{E}$ ) had no effect on splicing. Preserved splicing even in the absence of the branch point consensus sequence CURAY in Mt-Br2 indicates that an "a" residue somewhere in intron 10 serves as a branch point, and confirms that the position and context of the branch point sequence is degenerative in mammals.
A

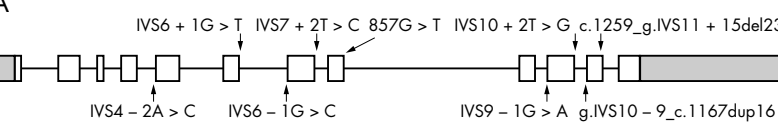

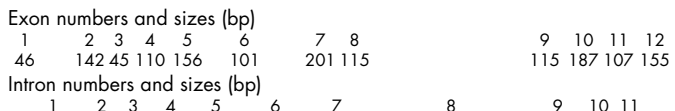

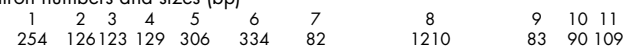

B

$\square \square \square \square \widehat{\square} \square \square$

IVS4 - 2A > C: Skipping of exon 5

$\square \square \square \square \square \widehat{\square} \square \square$

IVS6 - IG > T: Skipping of exon 6

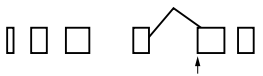

IVS6 -1 - $>$ > C: Activation of acryptic $3^{\prime}$ splice site

$\frac{\operatorname{lntron} 6}{\text { cagctgaccgtgeccegteccgeagAGAACGGCGAGTGG }}$

c
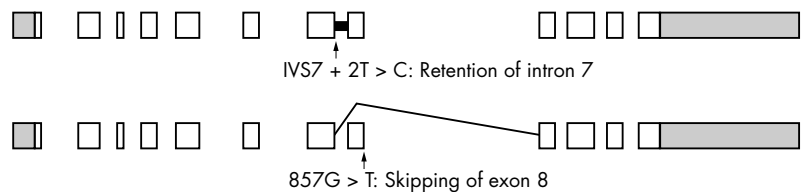

$857 G>$ T: Skipping of exon 8 $\underset{\text { CTGAGCGTGCCGCTCCTGGGCAGgtgaagccggagcCCCCgcgggg }}{\frac{1}{\mathrm{~T}}}$

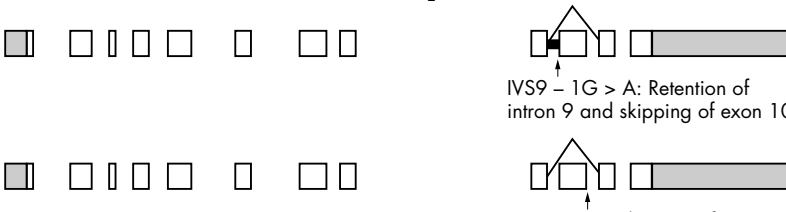

IVS10 + 2T > G: Skipping of exon 10

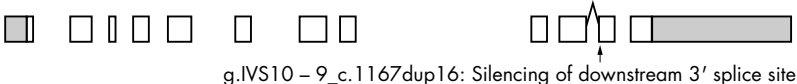
g.IVS10 - 9_c. 1167dup16: Silencing of downstream 3' splice site Intron 10 Exon 11

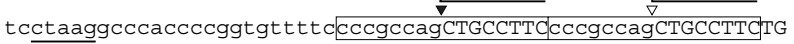
16 bp depletion

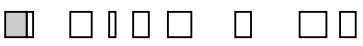

c.1259_g.IVS11 + 15del23: Retention of intron 11

Exon 11 Intron 11

CGAGAGATCAGGAGGCCACCGGCGAGGtgggacaggagccagagg goggtggagcgag 23 bp depletion

Figure 1 Nine analysed CHRNE mutations affecting pre-mRNA splicing. (A) The CHRNE gene structure is drawn to scale. Shaded areas indicate untranslated regions. Sizes of exons 1 and 12 represent those of the coding regions. (B) Schematic presentation of identified splicing consequences. Exon skipping and activation of a cryptic splice site are represented by thin oblique lines connecting two remote points. Intron retention is represented by a thick horizontal line. Four splicing

mutations are shown in detail, with partial CHRNE sequence below each scheme. Open and closed arrowheads indicate inactive and active splice sites, respectively. Putative branch point sequences are underlined.

We next swapped the seven residue segments and placed the native branch point sequence 16 residues downstream (MtBr4 in fig 2E). Mt-Br4 activated both the upstream and downstream copies of the $3^{\prime}$ splice sites, probably because the shortened polypyrimidine tract rendered the upstream copy of the splice acceptor site less competitive than the downstream copy. 
Table 2 Four previously reported splice site mutations in CHRNE

\begin{tabular}{lll}
\hline Mutation & $\begin{array}{l}\text { Position on genomic } \\
\text { DNA }\end{array}$ & Splicing consequence \\
\hline g.IVS4-2A $\rightarrow C^{4}$ & 3' $^{\prime}$ splice site of intron 4 & Skipping of exon 5 \\
g.IVS6+1G $\rightarrow \mathrm{T}^{19}$ & 5' $^{\prime}$ splice site of intron 6 & Skipping of exon 6 \\
g.IVS7 $+2 T \rightarrow \mathrm{C}^{20}$ & 5' splice site of intron 7 $^{\text {Retention of intron 7 }}$ \\
g.IVS10+2T $\rightarrow \mathrm{G}^{21}$ & 5' splice site of intron 10 & Skipping of exon 10 \\
\hline
\end{tabular}

DISCUSSION

Sizes of flanking introns predict exon skipping or intron retention

We analysed splicing consequences of nine mutations in CHRNE. Three other splicing mutations had been previously characterised..$^{2-4}$ To summarise, exons 5, 6, 8, 9, and 10 are skipped, and introns 7, 9, and 11 are retained. The three retained introns are all short (intron 7, $82 \mathrm{bp}$; intron 9, $83 \mathrm{bp}$; and intron 11, $109 \mathrm{bp}$ ), whereas four of five skipped exons flank medium to long introns on either or both sides (exon 5 is flanked by 129 and 306 bp introns; exon 6 by 306 and 334 bp introns; exon 8 by 82 and 1210 bp introns; and exon 9 by 1210 and $83 \mathrm{bp}$ introns). This is in accordance with collation of splicing mutations, ${ }^{6}$ and is consistent with the model of exon recognition in vertebrate splicing. ${ }^{7}$ Exon 10 , however, is flanked by 83 and 90 bp introns, and is skipped by two distinct mutations, indicating that the size of the flanking introns is only one of several factors that determine the splicing consequence. Indeed, even when we eliminated $1127 \mathrm{bp}$ in the middle of intron 8 (IVS8+17 to IVS8-59) to reduce its size to $83 \mathrm{bp}$, both IVS7-2A $\rightarrow \mathrm{G}$ and $857 \mathrm{G} \rightarrow \mathrm{T}$ still resulted in skipping of exon 7 (data not shown).

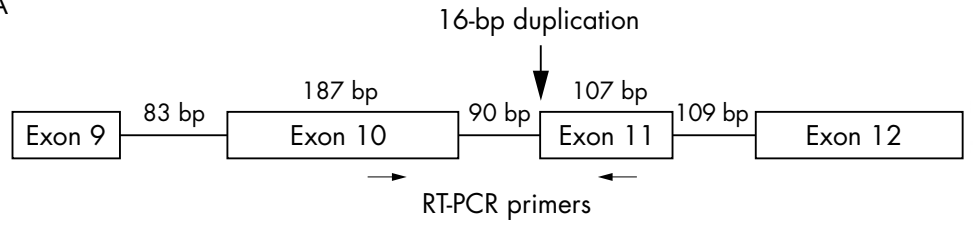

B

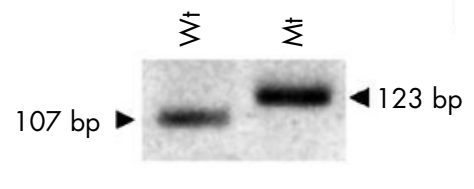

C

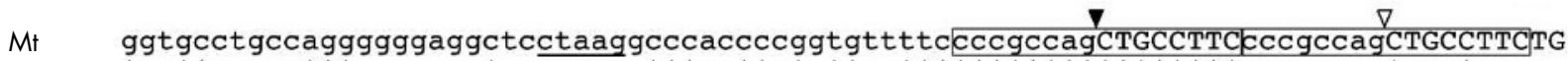

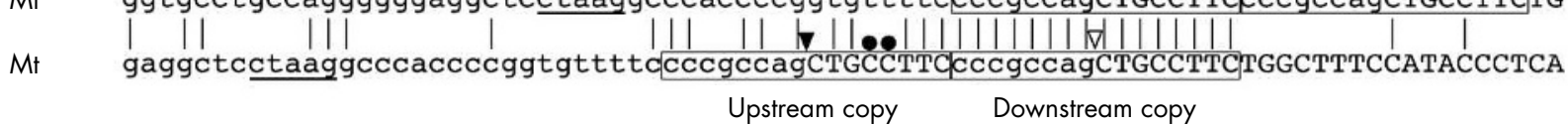

D

$\mathrm{Mt}$

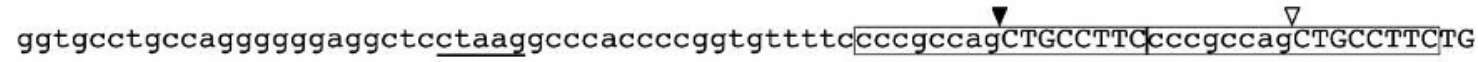

Mt-AC

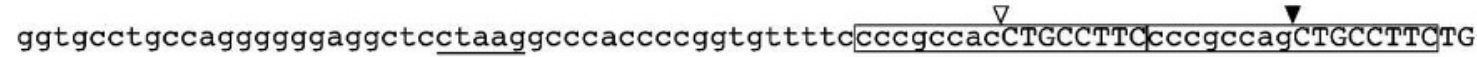

Mt-TC ggtgcetgccaggggggaggctcctaaggcceaccceggtgttttceccgccagCTGTCTTCCCCgCcagCTGCCTTCTG

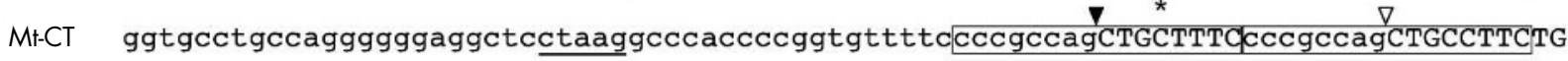

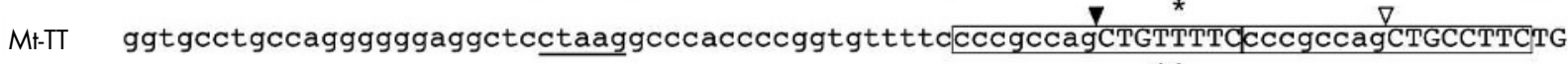

$\mathrm{E}$

$\mathrm{Mt}$

$\mathrm{Mt}-\mathrm{Br} \mathrm{l}$

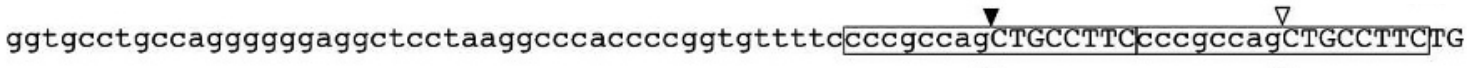

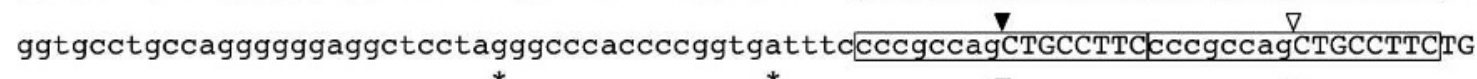

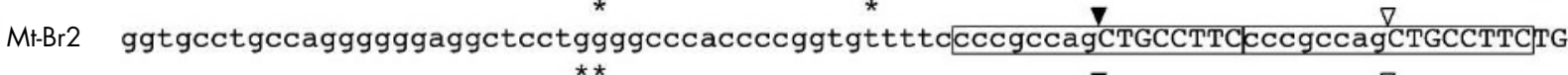
Mt-Br3 ggtgcetgceaggggggaggetcetggggeccaccceggtgatttecCcgccagCTGCCTTCCCCgCCagCTGCCTTCTG

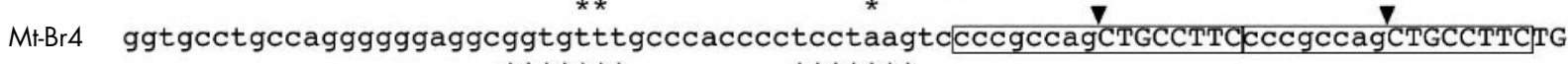

Figure 2 A 16 bp duplication of the 3' splice site of CHRNE intron 10/exon 11 boundary results in silencing of the downstream copy of the 3' splice sites by competition against the upstream copy. (A) A minigene spanning exons 9-12, which is inserted into a CMV based expression vector. (B) RTPCR analysis of cytoplasmic RNA of transfected COS cells shows that only the upstream copy of the splice acceptor site is active. (C) Alignment of active (closed arrowhead) and inactive (open arrowhead) 3' splice sites of the mutant (Mt) intron 10/exon 11 boundary. The two sequences are identical, but are shifted by $16 \mathrm{bp}$. Vertical lines indicate identical nucleotides. Duplicated $3^{\prime}$ splice sites are enclosed by boxes. Putative branch point sequence (CTRAY with an invariant A) is underlined. Upper and lower case letters represent exonic and intronic nucleotides, respectively. Dots point to mismātches that are corrected in Mt-TC, Mt-CT, and Mt-TT in panel D. (D) Disruption of an "ag" dinucleotide in the upstream copy activates the downstream copy (Mt-AC), whereas partial (Mt-TC and Mt-CT) or complete (Mt-TT) restoration of a "tnt" stretch in the polypyrimidine tract has no effect. Closed and open arrowheads point to active and inactive 3' splice sites, respectively. Asterisks indicate artificially mutated nucleotides. (E) Partial displacement of the native branch point $(\mathrm{Mt}-\mathrm{Br} 1)$, disruption of the branch point $(\mathrm{Mt}-\mathrm{Br} 2)$, or both $(\mathrm{Mt}-\mathrm{Br} 3)$ fails to activate the downstream copy of the duplicated 3' splice sites, whereas swapping of the seven residue segments $(\mathrm{Mt}-\mathrm{Br} 4)$ activates both the upstream and downstream copies. 

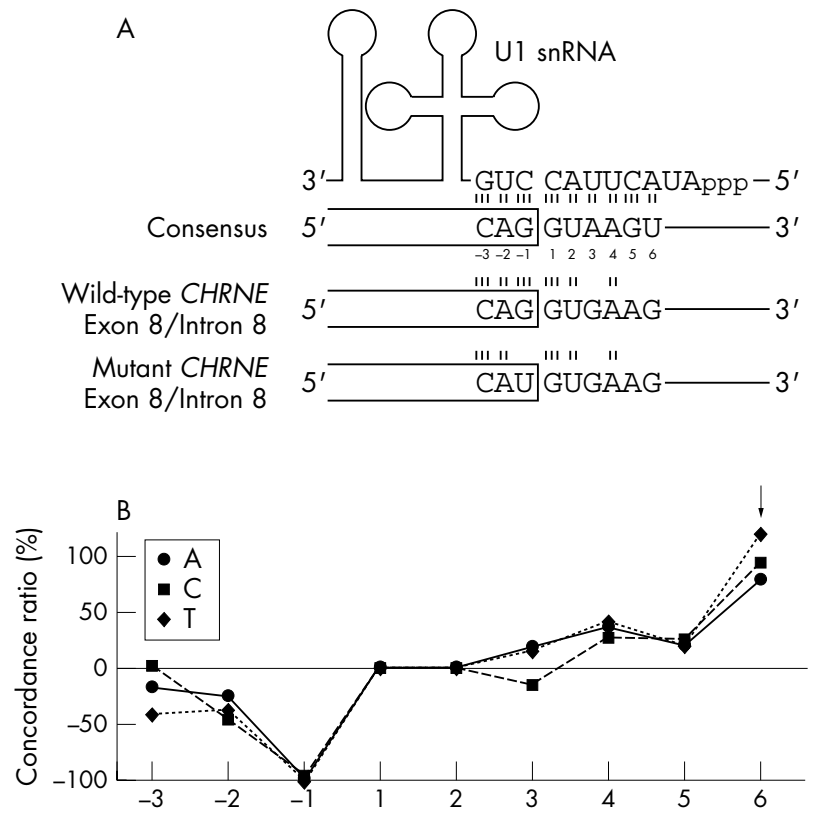

Figure 3 (A) U1 snRNA recognises three nucleotides at the $3^{\prime}$ end of an exon and six nucleotides at the $5^{\prime}$ end of an intron. The complementary nucleotides to UI snRNA constitute the consensus sequence. Wild type CHRNE exon 8 /intron 8 has mismatched nucleotides at positions $+3,+5$, and +6 . The $857 \mathrm{G} \rightarrow$ T mutation introduces another mismatch at position -1 . (B) A mismatch at the last nucleotide of an exon (position -1) to U1 snRNA is mostly compensated for by a match at position +6 in 1801 human exons. The ratios of $A, C, G$, and T at position -1 are $8.8 \%$, $3.3 \%, 80.3 \%$, and $7.5 \%$, respectively, in 1801 human exons. ${ }^{17}$ When a concordant $G$ is used at position -1 , the ratio of concordant $T$ at position +6 is $38.9 \%$. In contrast, when a discordant $T$ is used at position -1 , the ratio of concordant $T$ at position +6 is $85.9 \%$. The concordance ratio was calculated by (85.9-38.9)/38.9=121\% (arrow). A positive concordance ratio at a specific position indicates that a nucleotide complementary to U1 snRNA is preferentially used to compensate for a mismatch at position -1 .

\section{Why does a mutation at the $3^{\prime}$ end of an exon affect pre-mRNA splicing?}

Analysis of 1801 human $5^{\prime}$ splice sites $^{17}$ revealed that a mismatch at position -1 to Ul snRNA is mostly compensated for by a match at position +6 (fig 3). As CHRNE intron 8 has a mismatch at position +6 (fig 1 ), $857 \mathrm{G} \rightarrow \mathrm{T}$ at position -1 probably prevents UI snRNA from recognising the $5^{\prime}$ splice site of intron 8 , and hence causes skipping of exon 8 .

To date, 23 splicing mutations of the last nucleotide of an exon have been reported in human to date (table 3). In 17 mutations, the nucleotide at position +6 does not match to Ul snRNA (underlined nucleotides in table 3 ). In six other mutations that have a matched $\mathrm{T}$ nucleotide at position +6 , 12 out of 18 nucleotides at positions +3 to +5 are mismatched, whereas in 836 human $5^{\prime}$ splice sites that carry a matched $\mathrm{T}$ nucleotide at position +6 , only 766 out of 2508 nucleotides are mismatched $^{17}$ (Fisher's exact test, $p=0.003$ ). These observations also support the idea that a mismatch at position -1 is compensated for by matches at positions +3 to +6 , especially at position +6 .

\section{Duplication of the $3^{\prime}$ splice site}

We constructed and analysed a series of artificial mutants to understand the mechanism by which the duplicated 3' splice sites resulting from g.IVS10-9_c.1167dupl6 silence the downstream copy. Scanning model of recognition of the 3' splice site indicates that the first "ag" dinucleotide after the branch point is used for splicing catalysis. ${ }^{8} 9$ Three exceptions
Table 3 The 23 previously published splicing mutations at the last nucleotide of an exon

\begin{tabular}{|c|c|c|c|c|}
\hline Gene & Exon & $\begin{array}{l}\text { Wild type } \\
\text { sequence }\end{array}$ & $\begin{array}{l}\text { Mutant } \\
\text { nucleotide } \\
\text { at }-1\end{array}$ & $\begin{array}{l}\text { Wild type } \\
\text { nucleotide } \\
\text { at }+6\end{array}$ \\
\hline ATM $^{22}$ & 1 & AAGgtagga & $A$ & $a$ \\
\hline CFTR $^{23}$ & 2 & CAGgtacta & C & $\underline{a}$ \\
\hline$C P S 1^{24}$ & 8 & AAGgtgcaa & $\mathrm{C}$ & $\bar{a}$ \\
\hline CYP $27^{25}$ & 6 & $\bar{G} C G$ gtagga & A & $\frac{a}{a}$ \\
\hline$F A H^{26}$ & 2 & $\overline{\mathrm{CA}}$ Ggtagga & $\mathrm{T}$ & $\bar{a}$ \\
\hline$H_{E X A^{27}}$ & 3 & GAGgtaaca & A & $\frac{a}{a}$ \\
\hline IL2RG ${ }^{28}$ & 6 & $\bar{A} C G g t g a g a$ & $A$ & $\bar{a}$ \\
\hline$P K L R^{29}$ & 9 & GCGgtaggà & $A$ & $\overline{\mathrm{a}}$ \\
\hline$P_{R O C^{30}}$ & 7 & $\overline{\mathrm{CA}}$ Ggtggga & C & $\bar{a}$ \\
\hline $\operatorname{COLIAl^{31}}$ & 6 & ATGgigage- & A & $\bar{c}$ \\
\hline COLIA2 $2^{32}$ & 6 & ATGgtatgc & A & $\bar{c}$ \\
\hline $\operatorname{COL} 3 A I^{33}$ & 3 & $\overline{\mathrm{AA}}$ Ggtāicc & $A$ & $\bar{c}$ \\
\hline CYP27A $7^{34}$ & 3 & $\bar{A} A G g t a c \overline{c C}$ & C & $\bar{c}$ \\
\hline$L_{I P A^{35}}$ & 8 & $\bar{C}$ AGgtaggc & A & $\bar{c}$ \\
\hline LIPA $^{36}$ & 8 & CAGgtagg & A & $\frac{c}{c}$ \\
\hline CDKN2A $A^{37}$ & 2 & CAGgtgagg & $\mathrm{T}$ & $\frac{-}{g}$ \\
\hline$U_{R O S}^{38}$ & 4 & AAGgtgagg & $T$ & $\frac{\mathrm{g}}{\mathrm{g}}$ \\
\hline ATM $^{22}$ & 2 & ĀAGtatat & $A$ & $\frac{y}{t}$ \\
\hline$H B B^{39}$ & 1 & CAGgittggt & C & $t$ \\
\hline SERPINC $1^{40}$ & 3 & AAGgtgagt & A & $t$ \\
\hline$X P A^{41}$ & 3 & CAGgtactt & A & $t$ \\
\hline$X P A^{41}$ & 4 & CAGgtctct & C & $t$ \\
\hline$X P A^{42}$ & 5 & AAGgtagat & C & $t$ \\
\hline
\end{tabular}

have been reported: ${ }^{10-12}(a)$ an "ag" dinucleotide less than 13 nucleotides downstream of the branch point is not recognised, probably due to steric effects of trans acting elements; (b) the first "ag" dinucleotide is hidden in a stable secondary structure; and (c) two "ag" dinucleotides that are $<12$ nucleotides apart compete for being recognised by the splicesome. As the naturally occurring duplication mutant and all artificial mutants except for Mt-Br4 conform to none of the exceptions, they followed the scanning model that favours the first "ag" after the branch point. On the other hand, displacement of a branch point sequence 16 residues downstream (Mt-Br4 in fig 2) placed the "ag" dinucleotide $<13$ nucleotides downstream of the branch point, and made the upstream copy less competitive than the downstream copy.

Pathogenic duplication of the $3^{\prime}$ splice site has been reported in two other human genes. Both follow the scanning model of recognition of the $3^{\prime}$ splice site. An 18 nucleotide duplication comprising 16 intronic and 2 exonic residues of HEXB encoding the $\beta$ subunit of $\beta$-hexosaminidase results in an active upstream copy of the $3^{\prime}$ splice sites. ${ }^{13}$ A 69 nucleotide duplication comprising 7 intronic and 62 exonic residues of SLC4AI encoding anion exchanger member 1 also results in an active upstream copy of the $3^{\prime}$ splice sites. ${ }^{14}$

Thus, the scanning model of recognition of the $3^{\prime}$ splice site applies to most physiological and pathological duplications of the 3' splice sites, though exceptions do occur and await explanation. ${ }^{101516}$

\section{ACKNOWLEDGEMENTS}

This work was supported by the National Institutes of Health grant NS6277 and by a Muscular Dystrophy Association research grant to A G Engel. We thank Drs Y Harati (patient 2), B Anlar (patient 3), and D Weinberg (patient 5) for patient referral.

\section{Authors' affiliations}

K Ohno, A Tsujino, X-M Shen, M Milone, A G Engel, Department of Neurology and Neuromuscular Research Laboratory, Mayo Clinic, Rochester, MN 55905, USA 
K Ohno, Division of Neurogenetics and Bioinformatics, Department of Advanced Medical Science, Nagoya University Graduate School of Medicine, 65 Tsurumai, Showa, Nagoya 466-8550, Japan

Competing interests: none declared

Correspondence to: Dr K Ohno, Division of Neurogenetics and Bioinformatics, Department of Advanced Medical Science, Nagoya University Graduate School of Medicine, 65 Tsurumai, Showa, Nagoya 466-8550, Japan; ohnok@med.nagoya-u.ac.jp

Received 20 August 2004

Revised 25 February 2005

Accepted 15 March 2005

\section{REFERENCES}

1 Engel AG, Ohno K, Sine SM. Neurological diseases: Sleuthing molecular targets for neurological diseases at the neuromuscular junction. Nat Rev Neurosci 2003:4:339-52.

2 Barisic N, Schmidt C, Sidorova OP, Herczegfalvi A, Gekht BM, Song IH, Stucka R, Karcagi V, Abicht A, Lochmuller H. Congenital myasthenic syndrome (CMS) in three European kinships due to a novel splice mutation (IVS7-2A/G) in the epsilon acetylcholine receptor (AChR) subunit gene. Neuropediatrics 2002;33:249-54.

3 Croxen R, Young C, Slater C, Haslam S, Brydson M, Vincent A, Beeson D. End-plate gamma- and epsilon-subunit mRNA levels in AChR deficiency syndrome due to epsilon-subunit null mutations. Brain 2001;124:1362-72.

4 Ohno K, Milone M, Shen XM, Engel AG. A frameshifting mutation in CHRNE unmasks skipping of the preceding exon. Hum Mol Genet 2003;12:3055-66.

5 Roscigno RF, Weiner M, Garcia BM. A mutational analysis of the polypyrimidine tract of introns. Effects of sequence differences in pyrimidine tracts on splicing. J Biol Chem 1993;268:11222-9.

6 Nakai K, Sakamoto H. Construction of a novel database containing aberrant splicing mutations of mammalian genes. Gene 1994;141:171-7.

7 Berget SM. Exon recognition in vertebrate splicing. J Biol Chem 1995;270:2411-14

8 Smith CW, Porro EB, Patton JG, Nadal-Ginard B. Scanning from an independently specified branch point defines the $3^{\prime}$ splice site of mammalian introns. Nature 1989;342:243-7.

9 Chen S, Anderson K, Moore MJ. Evidence for a linear search in bimolecular 3' splice site AG selection. Proc Natl Acad Sci USA 2000;97:593-8.

10 Blasband AJ, Rogers KT, Chen XR, Azizkhan JC, Lee DC. Characterization of the rat transforming growth factor alpha gene and identification of promoter sequences. Mol Cell Biol 1990;10:2111-21.

11 Smith CW, Chu TT, Nadal-Ginard B. Scanning and competition between AGs are involved in $3^{\prime}$ splice site selection in mammalian introns. Mol Cell Biol 1993; 13:4939-52.

12 Chua K, Reed R. The RNA splicing factor hSlu7 is required for correct 3' splice-site choice. Nature 1999;402:207-10.

13 Dlott B, d'Azzo A, Quon DV, Neufeld EF. Two mutations produce intron insertion in mRNA and elongated beta-subunit of human betahexosaminidase. J Biol Chem 1990;265:17921-7.

14 Bianchi P, Zanella A, Alloisio N, Barosi G, Bredi E, Pelissero G, Zappa M, Vercellati C, Baronciani L, Delaunay J, Sirchia G. A variant of the EPB3 gene of the anti-Lepore type in hereditary spherocytosis. $\mathrm{Br} J$ Haematol 1997; $98: 283-8$.

15 Eller P, Foger B, Gander R, Sauper T, Lechleitner M, Finkenstedt G, Patsch JR Wolfram syndrome: a clinical and molecular genetic analysis. J Med Genet $2001 ; 38: e 37$

16 Penalva LO, Lallena MJ, Valcarcel J. Switch in $3^{\prime}$ splice site recognition between exon definition and splicing catalysis is important for sex-lethal autoregulation. Mol Cell Biol 2001;21:1986-96.

17 Ohno K, Brengman JM, Felice KJ, Cornblath DR, Engel AG Congenital endplate acetylcholinesterase deficiency caused by a nonsense mutation and an $A \rightarrow G$ splice-donor-site mutation at position +3 of the collagenlike-tail-subunit gene (COLQ): How does $G$ at position+3 result in aberrant splicing? Am J Hum Genet 1999:65:635-44.

18 Ohno K, Quiram PA, Milone M, Wang HL, Harper MC, Pruitt JN 2nd, Brengman JM, Pao L, Fischbeck KH, Crawford TO, Sine SM, Engel AG Congenital myasthenic syndromes due to heteroallelic nonsense/missense mutations in the acetylcholine receptor $\epsilon$ subunit gene: identification and functional characterization of 6 new mutations, Hum Mol Genet 1997;6:753-66.

19 Deymeer F, Serdaroglu P, Poda M, Gulsen-Parman Y, Ozcelik T, Ozdemir C Clinical characteristic of a group of Turkish patients having a benign CMS phenotype with ptosis and marked ophthalmoparesis and mutations in the acetylcholine receptor epsilon subunit gene. Acta Myologica 2000;19:29-32.

20 Ohno K, Anlar B, Ozdirim E, Brengman JM, DeBleecker JL, Engel AG. Myasthenic syndromes in Turkish kinships due to mutations in the acetylcholine receptor. Ann Neurol 1998:44:234-41.
21 Middleton L, Ohno K, Christodoulou K, Brengman J, Milone M, Neocleous V, Serdaroglu P, Deymeer F, Ozdemir C, Mubaidin A, Horany K, Al-Shehab A, Mavromatis I, Mylonas I, Tsingis M, Zamba E, Pantzaris M, Kyriallis K, Engel AG. Chromosome 17p-linked myasthenias stem from defects in the acetylcholine receptor epsilon-subunit gene. Neurology 1999:53:1076-82.

22 Teraoka SN, Telatar M, Becker-Catania S, Liang T, Onengut S, Tolun A, Chessa L, Sanal O, Bernatowska E, Gatti RA, Concannon P. Splicing defects in the ataxia-telangiectasia gene, ATM: underlying mutations and consequences. Am J Hum Genet 1999:64:1617-31.

23 Jones CT, Mclntosh I, Keston M, Ferguson A, Brock DJ. Three novel mutations in the cystic fibrosis gene detected by chemical cleavage: analysis of variant splicing and a nonsense mutation. Hum Mol Genet 1992;1:11-17.

24 Hoshide R, Matsuura T, Haraguchi Y, Endo F, Yoshinaga M, Matsuda I. Carbamyl phosphate synthetase I deficiency. One base substitution in an exon of the CPS I gene causes a 9-basepair deletion due to aberrant splicing. J Clin Invest 1993:91:1884-7.

25 Chen W, Kubota S, Seyama Y. Alternative pre-mRNA splicing of the sterol 27hydroxylase gene (CYP 27) caused by a $G$ to $A$ mutation at the last nucleotide of exon 6 in a patient with cerebrotendinous xanthomatosis (CTX). J Lipid Res 1998;39:509-17.

26 Rootwelt H, Berger R, Gray G, Kelly DA, Coskun T, Kvittingen EA. Novel splice, missense, and nonsense mutations in the fumarylacetoacetase gene causing tyrosinemia type 1. Am J Hum Genet 1994;55:653-8

27 Ozkara HA, Sandhoff K. A new point mutation (G412 to A) at the last nucleotide of exon 3 of hexosaminidase alpha-subunit gene affects splicing. Brain Devt 2003;25:203-6.

28 Kanai N, Yanai F, Hirose S, Nibu K, Izuhara K, Tani T, Kubota T, Mitsudome A. A G to A transition at the last nucleotide of exon 6 of the gamma $c$ gene $(868 \mathrm{G} \rightarrow \mathrm{A}$ ) may result in either a splice or missense mutation in patients with X-linked severe combined immunodeficiency. Hum Genet 1999; 104:36-42

29 Kanno H, Fujii H, Wei DC, Chan LC, Hirono A, Tsukimoto I, Miwa S. Frame shift mutation, exon skipping, and a two-codon deletion caused by splice site mutations account for pyruvate kinase deficiency. Blood 1997;89:4213-18.

30 Lind B, van Solinge WW, Schwartz M, Thorsen S. Splice site mutation in the human protein $\mathrm{C}$ gene associated with venous thrombosis: demonstration of exon skipping by ectopic transcript analysis. Blood 1993;82:2423-32.

31 Weil D, D'Alessio M, Ramirez F, de Wet W, Cole WG, Chan D, Bateman JF. A base substitution in the exon of a collagen gene causes alternative splicing and generates a structurally abnormal polypeptide in a patient with EhlersDanlos syndrome type VII. EMBO J 1989;8:1705-10.

32 Weil D, D'Alessio M, Ramirez F, Steinmann B, Wirtz MK, Glanville RW Hollister DW. Temperature-dependent expression of a collagen splicing defect in the fibroblasts of a patient with Ehlers-Danlos syndrome type VII. J Biol Chem 1989:264:16804-9

33 Kuivaniemi H, Tromp G, Bergfeld WF, Kay M, Helm TN. Ehlers-Danlos syndrome type IV: a single base substitution of the last nucleotide of exon 34 in COL3A1 leads to exon skipping. J Invest Dermatol 1995; 105:352-6.

34 Garuti R, Lelli N, Barozzini M, Tiozzo R, Dotti MT, Federico A, Ottomano AM, Croce A, Bertolini S, Calandra S. Cerebrotendinous xanthomatosis caused by two new mutations of the sterol-27-hydroxylase gene that disrupt mRNA splicing. J Lipid Res 1996;37:1459-67.

35 Klima H, Ullrich K, Aslanidis C, Fehringer P, Lackner KJ, Schmitz G. A splice junction mutation causes deletion of a 72-base exon from the mRNA for lysosomal acid lipase in a patient with cholesteryl ester storage disease. J Clin Invest 1993;92:2713-18.

36 Aslanidis C, Ries S, Fehringer P, Buchler C, Klima H, Schmitz G. Genetic and biochemical evidence that CESD and Wolman disease are distinguished by residual lysosomal acid lipase activity. Genomics 1996;33:85-93.

37 Rutter JL, Goldstein AM, Davila MR, Tucker MA, Struewing JP CDKN2A point mutations D153spl(c. 457G $\rightarrow$ T) and IVS2+1G $\rightarrow$ T result in aberrant splice products affecting both pl6INK4a and pl4ARF. Oncogene 2003;22:4444-8

38 Xu W, Astrin KH, Desnick RJ. Molecular basis of congenital erythropoietic porphyria: mutations in the human uroporphyrinogen III synthase gene. Hum Mutat 1996:7:187-92.

39 Vidaud M, Gattoni R, Stevenin J, Vidaud D, Amselem S, Chibani J, Rosa J, Goossens $M$. A 5' splice-region $G \rightarrow C$ mutation in exon 1 of the human betaglobin gene inhibits pre-mRNA splicing: a mechanism for beta+-thalassemia. Proc Natl Acad Sci USA 1989:86:1041-5.

40 Berg LP, Grundy CB, Thomas F, Millar DS, Green PJ, Slomski R, Reiss J, Kakkar VV, Cooper DN. De novo splice site mutation in the antithrombin III (AT3) gene causing recurrent venous thrombosis: demonstration of exon skipping by ectopic transcript analysis. Genomics 1992;13:1359-61.

41 Satokata I, Tanaka K, Yuba S, Okada Y. Identification of splicing mutations of the last nucleotides of exons, a nonsense mutation, and a missense mutation of the XPAC gene as causes of group A xeroderma pigmentosum. Mutat Res 1992;273:203-12

42 Sato $M$, Nishigori C, Yagi T, Takebe H. Aberrant splicing and truncatedprotein expression due to a newly identified XPA gene mutation. Mutat Res 1996:362:199-208. 